\title{
New advances in in-situ thermal desorption technology for contaminated soil
}

\author{
SHI Yan, LUO ZiHao, WANG YiXuan ${ }^{*}$, CAI MaoLin \& YANG LiMan ${ }^{*}$ \\ School of Automation Science and Electrical Engineering, Beihang University, Beijing 100191, China
}

Received February 21, 2019; accepted July 24, 2019; published online September 24, 2019

\begin{abstract}
Citation: Shi Y, Luo Z H, Wang Y X, et al. New advances in in-situ thermal desorption technology for contaminated soil. Sci China Tech Sci, 2019, 62: 20752076, https://doi.org/10.1007/s11431-019-9619-3
\end{abstract}

With the development of ecological civilization and economic construction, remediation of contaminated soils has caused more and more concern of scientists and engineers. Situ thermal desorption is a mature and effective technology which is especially suitable for the contaminated soil of relocated chemical plant [1,2]. Compared with in-situ chemical oxidation and ectopic thermal desorption, the in-situ thermal desorption has stronger applicability and higher repair efficiency. The main applications of the in-situ thermal desorption technology are semi-volatile and volatile organic pollutants.

According to the different heat transfer methods and energy conversion, the in-situ thermal technologies can be divided into four types: steam/hot air injection (SAI), thermal conductive heating (TCH), electrical resistance heating $(\mathrm{ERH})$ and radio frequency heating $(\mathrm{RFH})$ [3].

(1) SAI transfers heat through convection by injecting water vapor or hot air into the contaminated area. The SAI technology is suitable for the repair of contaminated areas with good homogeneity and large hydraulic conductivity.

(2) TCH refers to the transfer of heat from a heat source to contaminated area by means of heat conduction. The TCH technology is suitable for contaminated land with poor permeability or poor homogenization. The soil gas phase extraction technology need be combined with TCH to achieve remediation of contaminated soils.

(3) ERH is based on Joule's law, converting electrical

\footnotetext{
*Corresponding authors (email: magic_wyx@163.com; ylm@buaa.edu.cn)
}

energy into heat to increase the temperature. This system includes power control facilities, electrodes, steam recovery facilities, and recycling processing systems.

(4) RFH uses electromagnetic waves generated by highfrequency voltages to heat contaminated areas. However, low-frequency electromagnetic waves have stronger penetration ability. The low-frequency electromagnetic waves are often used in in situ repair.

A typical in-situ thermal desorption soil remediation process may include heaters, off-gas collection piping, an offgas treatment system, and instrumentation and power control systems [4]. The heaters are determined by different types of the in-situ thermal technologies. The SAI technology uses steam generating device. The TCH technology uses thermal wells. The ERH technology uses electrical conductor, and the RFH technology uses electromagnetic waves. The offgas collection piping connects an array of suction wells to an off-gas treatment facility. Extraction pump, steam-water separation and off-gas collection piping composite the gas extraction and recovery system. The off-gas treatment system mainly includes gas-liquid separation, activated carbon adsorption and thermal oxidation. The adsorption and activated carbon adsorption are the main treatment methods for the remaining exhaust gas.

The most important three factors of the in-situ thermal desorption are: temperature, treatment time and soil properties. The spatial arrangement of the thermal wells will also affect the heating efficiency and economic benefits.

Temperature significantly affects the thermal desorption 
process of organic matter $[5,6]$. And some studies show that in-situ thermal desorption has different optimal temperatures for different contaminants [6]. When the temperature is lower than the optimum temperature, the contaminant removal efficiency increases as the temperature increases. While the removal efficiency declines with the temperature declines when the temperature is higher than the optimum temperature.

Treatment time of in-situ thermal desorption usually depends on factors such as initial contaminant concentration, target contaminant concentration, target treatment temperature, porosity, mineral composition and fluid extraction during heating. In general, the volatile organic compound is treated for 2 to 6 months and the semi-volatile organic compound is about 6 to 12 months.

Soil properties also influence the in-situ thermal desorption. Different soils have different thermal conductivity, thermal diffusivity and soil moisture content. Thermal conductivity and thermal diffusivity directly affect the thermal desorption process. Soil moisture is very important in steam distillation, competition with binding sites, increased solubility and promotion of pollutant degradation during thermal desorption.

The spatial arrangement of the thermal wells not only affects the thermal desorption efficiency, but also affects the cost of the thermal desorption engineering. Baker and Heron [7] summarized the commonly used spatial arrangement of the thermal wells.

Because of the high temperature of thermal desorption, soil properties will change. Some studies attempt to assess the effects of in-situ thermal desorption from measuring biological effects, soil organic matter, soil texture and mineralogy, soil $\mathrm{pH}$, plant available nutrients and heavy metals, soil biomes and soil conservation of vegetation [8].

In the last century, 80 in-situ thermal desorption systems began to be applied to soil surface restoration on contaminated sites [9]. At the beginning of the 20th century, the development of heating elements promotes the further development of thermal desorption. In recent years, systems and methods for modern sustainable restoration of groundwater and soil restoration, evaluation of in-situ thermal desorption processes [10] have also developed. This technology is getting maturer.
By studying recent research, we summarize the development trend of future in-situ thermal desorption technology into the following aspects:

(1) Innovation in heating methods and rational integration of different heating methods;

(2) Reasonable in-situ thermal desorption technology element matching mechanism for different pollutants and soil (such as temperature, treatment time and thermal wells arrangement);

(3) The soil recovery treatment after in-situ thermal desorption was studied. Make the entire soil management process a green, high-quality and effective system.

1 Aresta M, Dibenedetto A, Fragale C, et al. Thermal desorption of polychlorobiphenyls from contaminated soils and their hydrodechlorination using Pd- and Rh-supported catalysts. Chemosphere, 2008, 70: 1052-1058

2 Kastanek F, Topka P, Soukup K, et al. Remediation of contaminated soils by thermal desorption; effect of benzoyl peroxide addition. J Clean Prod, 2016, 125: 309-313

3 Kingston J L T, Johnson P C, Kueper B H, et al. In-situ thermal treatment of chlorinated solvent source zones. In: Kueper B, Stroo H, Vogel C, et al., eds. Chlorinated Solvent Source Zone Remediation. SERDP ESTCP Environmental Remediation Technology, Vol 7. New York: Springer, 2014. 509-557

4 Vinegar H J, Stegmeier G L. Low cost, self regulating heater for use in an in-situ thermal desorption soil remediation system. USA Patent, US6485232. 2002-11-26

5 Lee J K, Park D, Kim B U, et al. Remediation of petroleum-contaminated soils by fluidized thermal desorption. Waste Management, 1998, 18: 503-507

6 Heron G, Van Zutphen M, Christensen T H, et al. Soil heating for enhanced remediation of chlorinated solvents: A laboratory study on resistive heating and vapor extraction in a silty, low-permeable soil contaminated with trichloroethylene. Environ Sci Technol, 1998, 32: 1474-1481

7 Baker R S, Heron G. In-situ delivery of heat by thermal conduction and steam injection for improved DNAPL remediation. In: Proceedings of the 4th International Conference on Remediation of Chlorinated and Recalcitrant Compounds. Monterey: Battelle Press, 2004

8 O'Brien P L, DeSutter T M, Casey F X M, et al. Thermal remediation alters soil properties: A review. J Environ Manage, 2018, 206: 826835

9 Stegemeier G L, Vinegar H J. Thermal conduction heating for in-situ thermal desorption of soils. In: Chang H, ed. Hazardous \& Radioactive Waste Treatment Technologies Handbook. Boca Raton: CRC Press, 2001. $1-37$

10 U.S. Environmental Protection Agency. Superfund remedy report. 14th ed. Washington: U.S. Environmental Protection Agency, 2013. $7-$ 11 